University of Wollongong

Research Online

Faculty of Engineering and Information

Faculty of Engineering and Information

Sciences - Papers: Part A

Sciences

$1-1-2014$

\title{
Abnormal ductility increase of commercial purity Al during accumulative roll bonding
}

Kuiyu Cheng

University of Wollongong, kc938@uowmail.edu.au

Cheng Lu

University of Wollongong, chenglu@uow.edu.au

Kiet Tieu

University of Wollongong, ktieu@uow.edu.au

Follow this and additional works at: https://ro.uow.edu.au/eispapers

Part of the Engineering Commons, and the Science and Technology Studies Commons

Research Online is the open access institutional repository for the University of Wollongong. For further information contact the UOW Library: research-pubs@uow.edu.au 


\title{
Abnormal ductility increase of commercial purity Al during accumulative roll bonding
}

\author{
Abstract \\ In this paper, sheets of commercial purity Al were fabricated by the accumulative roll-bonding (ARB) \\ method up to six cycles. To increase the shear deformation, no lubricant was used during the ARB \\ processing and the samples were carried out for ARB processing without any preheat treatment. One \\ interesting finding is that the ductility and strength both increased during the first several cycles of ARB \\ processing. It is proposed that the initial rolling texture might play an important part in the subsequent \\ ARB processing since the original Al sheets for ARB processing have not been subjected to any \\ annealing. The microstructures of the specimens after each ARB cycle were investigated by transmission \\ electron microscopy and correlated with the mechanical properties.

\section{Keywords} \\ bonding, roll, accumulative, ductility, during, abnormal, al, purity, commercial, increase

\section{Disciplines} \\ Engineering | Science and Technology Studies

\section{Publication Details} \\ Cheng, K., Lu, C. \& Tieu, K. (2014). Abnormal ductility increase of commercial purity Al during \\ accumulative roll bonding. Metallurgical and Materials Transactions B: Process Metallurgy and Materials \\ Processing Science, 45 (2), 404-408.
}




\title{
Abnormal Ductility Increase of Commercial Purity Al During Accumulative Roll Bonding
}

\begin{abstract}
KUIYU CHENG, CHENG LU, and KIET TIEU
In this paper, sheets of commercial purity $\mathrm{Al}$ were fabricated by the accumulative roll-bonding (ARB) method up to six cycles. To increase the shear deformation, no lubricant was used during the ARB processing and the samples were carried out for ARB processing without any preheat treatment. One interesting finding is that the ductility and strength both increased during the first several cycles of ARB processing. It is proposed that the initial rolling texture might play an important part in the subsequent ARB processing since the original Al sheets for ARB processing have not been subjected to any annealing. The microstructures of the specimens after each ARB cycle were investigated by transmission electron microscopy and correlated with the mechanical properties.
\end{abstract}

DOI: $10.1007 / \mathrm{s} 11663-013-9843-7$

(C) The Minerals, Metals \& Materials Society and ASM International 2013

\section{INTRODUCTION}

NANOSTRUCTURED metals and alloys usually possess significant strengthening or large plasticity at high temperature. These materials can be produced by various techniques such as severe plastic deformation, electrodeposition, or mechanical milling of powder metals. $^{[1-8]}$ The severe plastic deformation methods, including high pressure torsion (HPT),${ }^{[9-12]}$ equal channel angular pressing (ECAP), ${ }^{[13-16]}$ and accumulative roll bonding $(\mathrm{ARB}),{ }^{[1-3]}$ have been intensively developed and applied in many industrial metals. Among these SPD methods, the ARB is the most promising one to produce large bulk materials. ${ }^{[1-3]}$ However, the nanostructured materials fabricated by the ARB method usually exhibit little tensile ductility and especially unapparent superplasticity. ${ }^{[17-20]}$ Therefore, post-processing of ARB materials, such as annealing and a combination with other SPD methods, ${ }^{[18-20]}$ has been attempted to obtain both high strength and good plasticity. Interestingly, in a Huang et al.' $\mathrm{s}^{[18]}$ study, the structure and the mechanical properties of nanostructured $\mathrm{Al}$ annealed at a low temperature were investigated and an unexpected phenomenon, a hardening rather than softening accompanied with a decrease rather than an increase in elongation, was observed. Later, based on a successful introduction of a cold rolling step following roll bonding, deformation rather than annealing was proposed by Huang et al. ${ }^{[19]}$ to be an approach to improve the ductility of nanostructured metals. The authors proposed that the beneficial effect of low temperature annealing/deformation is related to the limitation/introduction of dislocation resources. ${ }^{[18,19]}$

KUIYU CHENG, Student, CHENG LU, Senior Lecturer, and KIET TIEU, Professor, are with the Mechanical School, Faculty of Engineering, University of Wollongong, Northfields Avenue, Wollongong, NSW 2522, Australia. Contact e-mail: chenglu@uow.edu.au

Manuscript submitted March 4, 2013.

Article published online April 13, 2013.
More recently, Kamikawa et al. ${ }^{[20]}$ have proposed that a heat treatment at intermediate temperature could give a satisfactory combination of strength and ductility, which is not obtained either in the deformed state or after annealing at high temperature. They investigated the strength-structure relationships and also related this unusual phenomenon to the so-called dislocation sourcelimited hardening. ${ }^{[20]}$

In the present study, the rolling sheets of commercial purity Al were used for ARB processing without any preheat treatment. It is found that both high strength and increased ductility were achieved relatively during the first ARB cycles (1st-3rd). Microstructure evolution during the ARB processing was investigated by the focus ion beam method and transmission electron microscopy. The abnormal increase of ductility is suggested to be related to the modification of the initial deformed microstructure by ARB processing.

\section{EXPERIMENTAL}

Commercial purity Al 1050 was used in this study and Table I lists the detailed composition. The rolled samples were cut parallel to the original rolling direction (RD), having the dimension of $1.36 \mathrm{~mm} \times 50 \mathrm{~mm} \times 200 \mathrm{~mm}$ (thickness $\times$ width $\times$ length). Although fully recrystallized materials are usually used as the starting materials for ARB processing, all the samples were not annealed before ARB processing in the present study. Then, two strip samples were stacked, welded at one end, and roll bonded in each pass rolling with a thickness reduction of about 50 pct after degreasing and wire brushing the surfaces in between. The entire roll-bonding process was carried out at room temperature without any lubricant to increase the shear deformation. The samples (marked by $\mathrm{L}$ ) went for ARB processing without any preheat treatment. The detailed process parameters are shown in Table II. 
The roll-bonding process was done by a two-high experimental rolling mill. The rolls are have a $125 \mathrm{~mm}$ diameter and $280 \mathrm{~mm}$ barrel length, are made of Böhler W302 tool steel, and the roll peripheral speed is $196 \mathrm{~mm} / \mathrm{s}$. The roll surfaces have been ground and the roughness was $\mathrm{Ra}=0.28 \mu \mathrm{m}$ along the circumferential direction and $\mathrm{Ra}=0.34 \mu \mathrm{m}$ along the axial direction. The roll gap could be set by a mechanical screw-down system and two hydraulic capsules.

After each ARB processing, the tensile samples were machined from the ARB-processed samples along the rolling direction with a gage dimension of $25 \mathrm{~mm} \times$ $6 \mathrm{~mm}$ (length $\times$ width). The tensile tests were carried out on a servo-controlled Instron tensile machine at a speed of $0.025 \mathrm{~mm} / \mathrm{s}$ to failure and the true stress-true strain curves were then calculated. Subsequently, thin foils containing the normal direction (ND) and the rolling direction (RD) of deformed sheets were cut out from both the center and edge (near surface) positions of the selected ARB-deformed samples by the focus ion beam (FIB) method for transmission electron microscope (TEM) observations. The TEM observation was carried out on a JOEL JEM 2011 microscope operating at $200 \mathrm{kV}$. Under TEM observation, an area of about $6.3 \mu \mathrm{m}$ in diameter was used to obtain the grain orientation relationships by selected area diffraction (SAD) patterns.

\section{RESULTS}

\section{A. Mechanical Properties}

Tensile tests were carried out at room temperature for all samples with the same strain rate equivalent to $10^{-3} / \mathrm{s}$.

Table I. Chemical Composition of the Commercial Purity Aluminum 1050 Used in this Study

\begin{tabular}{ll}
\hline Element & Wt Pct \\
\hline $\mathrm{Cu}$ & $0-0.05$ \\
$\mathrm{Mg}$ & $0-0.05$ \\
$\mathrm{Si}$ & $0-0.25$ \\
$\mathrm{Fe}$ & $0-0.4$ \\
$\mathrm{Mn}$ & $0-0.05$ \\
$\mathrm{Zn}$ & $0-0.07$ \\
$\mathrm{Ti}$ & $0-0.05$ \\
$\mathrm{Al}$ & balance \\
\hline
\end{tabular}

Figure 1 shows typical examples of the true stress-strain curves of the ARB-deformed samples. First, the strength increased with the rolling cycles, which is consistent with most previous studies. Importantly, however, it is of much interest that the elongation to failure also increased during the first several cycles of ARB processing rather than decreasing. Moreover, these deformed samples exhibit large post-uniform elongation with the flow stress reducing very slowly.

To clearly show the variation trend of strength and elongation during ARB processing, the ultimate tensile strength and elongation against the ARB cycle are plotted in Figure 2. The ultimate tensile strength is the maximum strength on the true stress-true strain curve, while the elongation to failure is adopted to describe the ductility property. It can be seen that the strength increased sharply, as well as the elongation, up to the third ARB cycle. Then, the strength increased smoothly up to the fifth ARB cycle, while the elongation varied very little at the same stage. Finally, a further ARB cycle led to an obvious increase of the strength, but a sharp reduction of the elongation.

\section{B. Microstructure Evolution}

Figure 3 shows the TEM microstructure of the hotrolled $\mathrm{Al} 1050$ used as the starting material, and the direction for following ARB processing is also indicated. It can be seen that most of the grains are surrounded by

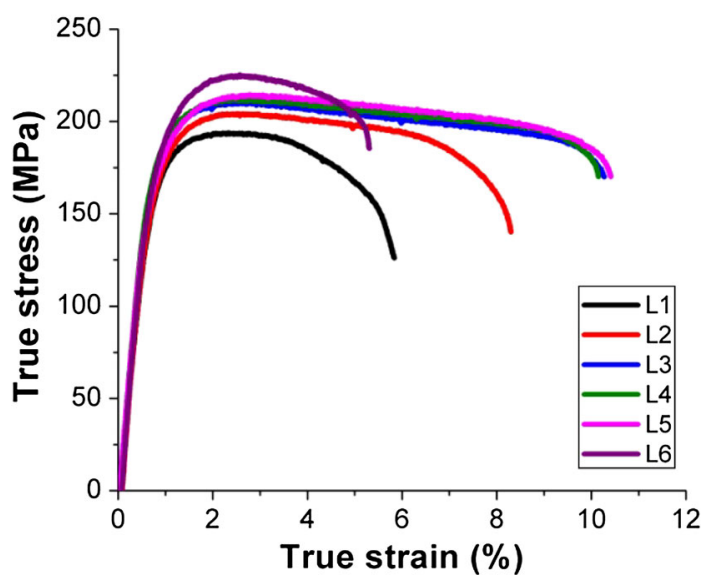

Fig. 1-Room temperature tensile tests for the ARB-deformed samples.

Table II. Process Parameters for the ARB Experiments

\begin{tabular}{|c|c|c|c|c|c|c|c|}
\hline Pass No. & $\begin{array}{c}\text { Entry } \\
\text { Thickness (mm) }\end{array}$ & $\begin{array}{c}\text { Exit } \\
\text { Thickness }(\mathrm{mm})\end{array}$ & $\begin{array}{c}\text { Rolling } \\
\text { Speed }(\mathrm{mm} / \mathrm{s})\end{array}$ & Reduction & $\begin{array}{l}\text { True Strain } \\
\text { (pct) }\end{array}$ & $\begin{array}{l}\text { Accumulative } \\
\text { True Strain }\end{array}$ & $\begin{array}{l}\text { Layers in } \\
\text { the Sample }\end{array}$ \\
\hline L1 & 2.700 & 1.278 & 196 & 0.52667 & 0.86015 & 0.86015 & 2 \\
\hline L2 & 2.556 & 1.148 & 196 & 0.55086 & 0.92049 & 1.78064 & 4 \\
\hline L3 & 2.296 & 1.020 & 196 & 0.55575 & 0.93307 & 2.71371 & 8 \\
\hline L4 & 2.040 & 0.981 & 196 & 0.51912 & 0.84195 & 3.55566 & 16 \\
\hline L5 & 1.962 & 0.929 & 196 & 0.5265 & 0.85975 & 4.41541 & 32 \\
\hline L6 & 1.838 & 0.804 & 196 & 0.56257 & 0.95086 & 5.36627 & 64 \\
\hline
\end{tabular}


clear grain boundaries and dislocations are found more or less in each grain by tilting the sample in the TEM. The inset shows the representative SAD patterns. The patterns are complicated and indicate the existence of a large local misorientation in this condition. ${ }^{[3]}$ Besides, the grains already exhibit certain elongation along the rolling direction in this condition. The average boundary spacings parallel to the rolling direction $\left(d_{l}\right)$ and perpendicular to the rolling plan $\left(d_{n}\right)$ were measured by the intersection method and are listed in Table III along with the aspect ratio $\left(d_{l} / d_{n}\right)$.

Microstructure evolution during the ARB processing is shown in Figure 4 and the structure parameters (except L6 center) are also given in Table III. The microstructure evolution can be summarized as

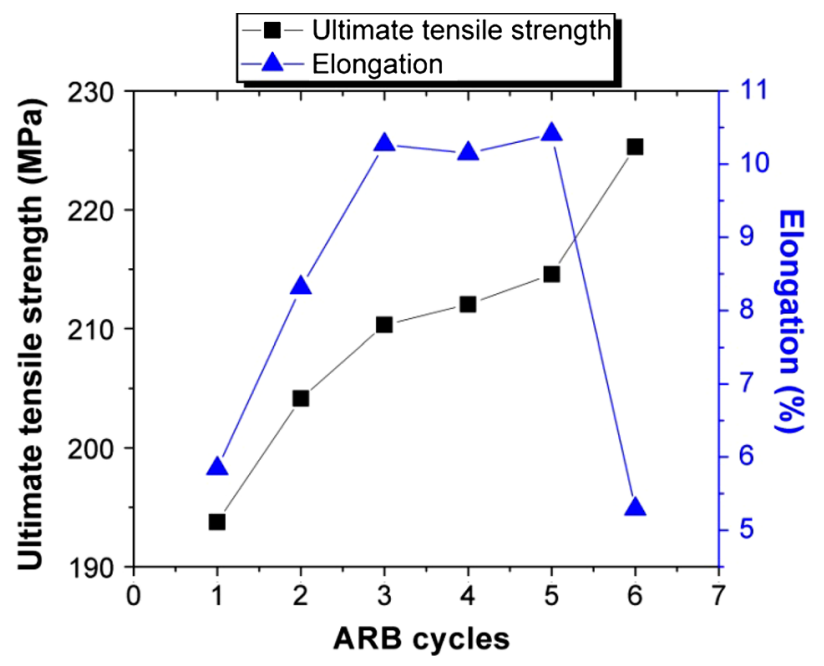

Fig. 2-Strengths and elongation as functions of rolling cycles' number.

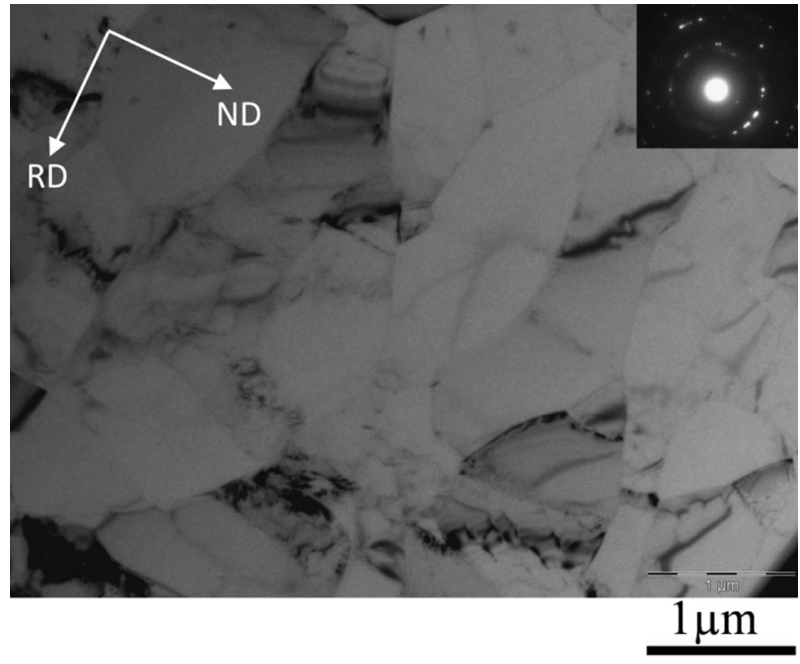

Fig. 3-Microstructure of the hot-rolled Al 1050 used as the starting material. Inset is the corresponding selected area diffraction patterns. RD and ND stand for rolling direction and normal direction, respectively. i) Above all, the ARB processing has refined the microstructure compared to that of the starting materials, especially for the boundary spacings perpendicular to the rolling direction $\left(d_{n}\right)$.

ii) In the center of the sample, the grains have been elongated and the aspect ratio increased evidently with increasing the first several cycles of ARB processing. Dislocations were found both on the grain boundaries and inside the grains, and the dislocation distribution seems uniform in these stages. The corresponding SAD patterns are similar to that of the starting material, complicated and indicating the existence of large local misorientation. However, the spots' distribution seems to gather in particular directions compared to the RD and ND after different cycles of ARB processing, which indicates that the relative grain misorientation has changed during ARB processing. After six cycles of ARB processing, the microstructure distribution is extremely nonuniform. Some areas (right side) show the ultrafine grain microstructure $\left(d_{n} \sim 250 \mathrm{~nm}\right)$ which results from the severe plastic deformation, and dislocations are distributed all through the area. The corresponding SAD patterns confirm the ultrafine grain microstructure by the diffraction rings. On the other hand, some areas (left side) present the recrystallization look micrograins, and the dislocations density becomes less obvious in this area. The corresponding SAD patterns display no regularity.

iii) In the edge position of the sample, the grains have been refined more obviously in both $d_{n}$ and $d_{l}$ during the first several ARB cycles compared to the center position due to the larger shear deformation. The grain aspect ratio is also smaller than that of the center position. It is also can be seen from the SAD patterns after three cycles of ARB processing; the incomplete diffraction rings imply that the fine microstructure already forms in this stage. For the first three cycles of ARB processing, the individual dislocations and dislocation tangles were found frequently, and the dislocation density increases with increasing the ARB cycles. After six cycles of ARB processing, the fine grains seem relatively equiaxed with an average size less than $500 \mathrm{~nm}$ and the aspect ratio is even a little smaller than that of the starting material. Moreover, the grain boundaries are very clear and the dislocation density in this stage is low. The corresponding SAD patterns show the incomplete rings as well, which indicates the

Table III. Structural Parameters in the Starting Material and the ARB-Deformed Samples

\begin{tabular}{lccc}
\hline Samples & $d_{l}(\mu \mathrm{m})$ & $d_{n}(\mu \mathrm{m})$ & Aspect Ratio \\
\hline Starting & 1.78 & 1.23 & 1.45 \\
L1 Center & 1.13 & 0.53 & 2.13 \\
L3 Center & 1.38 & 0.42 & 3.29 \\
L1 Edge & 1.07 & 0.56 & 1.91 \\
L3 Edge & 1.19 & 0.45 & 2.64 \\
L6 Edge & 0.54 & 0.39 & 1.38 \\
\hline
\end{tabular}


nearly ultrafine grain microstructure and the existence of large local grain misorientations.

\section{DISCUSSION}

The present experiment shows that the strength and ductility of the commercial purity Al sheets with initial hot rolling microstructure have been relatively increased during ARB processing at the beginning stages (1st3rd). Usually, the strength should be increased and the elongation should be reduced with increasing cycles of ARB processing. ${ }^{[1-3]}$ An unusual phenomenon like this has been intensively reported in ultrafine materials recently. Huang et al. ${ }^{[18]}$ have successively shown that a low temperature annealing of the nanostructured $\mathrm{Al}$ has led to a hardening rather than softening accompanied with a decrease rather than an increase in elongation, and that deformation rather than annealing has improved the ductility of nanostructured metals (Al and steel). ${ }^{[19]}$ Kamikawa et al.'s ${ }^{[20]}$ experiment has shown that a heat treatment at intermediate temperature could give a satisfactory combination of strength and ductility of the ultrafine pure Al. They proposed the limitation/ introduction of the dislocation resources theory to explain these unexpected phenomena in ultrafine or nanostructured materials. The microstructure investigation in the present study shows that the dislocation density increased during ARB processing at the beginning stages (1st-3rd). To some extent, the introduction of the dislocation resources theory might explain the relative improvement of the ductility with more ARB cycles. It should be noted that the limitation/introduction of the dislocation resources theory was proposed for ultrafine grain or nanostructured materials, whereas the microstructure during the first several cycles of ARB processing has not reached this level in the present study. Therefore, there must be some other deformation mechanism dominant in this stage.

As the starting material has certain hot rolling microstructure and the ARB processing was conducted at the room temperature, due to the different textures of hot rolling and cold rolling, ${ }^{[6]}$ the ARB processing might significantly change the grain misorientations and the relative relationships of slip systems of each grain. It is known that the diffraction spots are corresponding to different crystal planes of a crystal and that the distance of a diffraction spot to the center is the inverse of the corresponding crystal plane spacing. Therefore, for polycrystalline homogeneity materials, the electron diffraction spots from the same crystal plane family will form on the same ring. When there are sufficient grains that have arbitrary orientations within the selected area for electron diffraction, the SAD patterns will present diffraction rings like those in ultrafine or nanostructured materials. However, when the grains have certain common orientation characteristics, the diffraction spots would be correspondingly concentrated on certain positions of the ring. Therefore, SAD patterns can to some extent reflect the grain orientation relationships of the materials. Because of the electron diffraction characteristics of the FCC materials, the first inner ring is formed by the diffraction spots of the $\{111\}$ family, which are the slip planes and closely related to the plastic deformation behavior. It can be seen that the $\{111\}$ diffraction spots for the starting

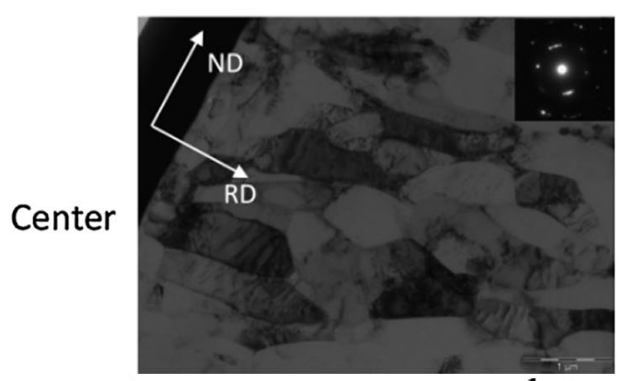

(a)

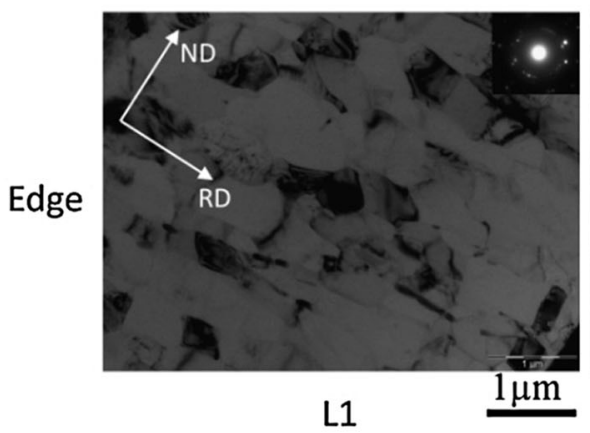

(d)

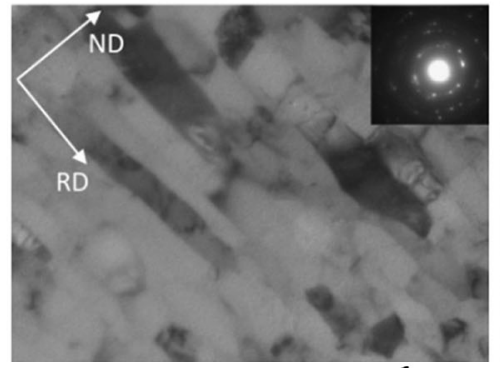

(b)

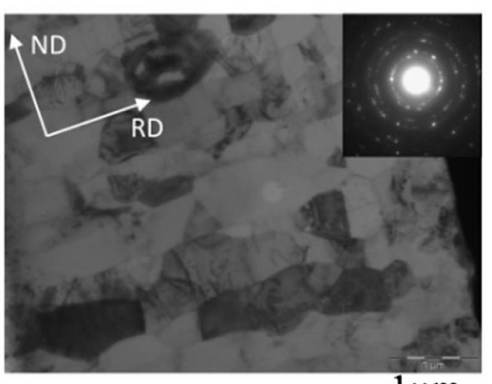

L3

(e)

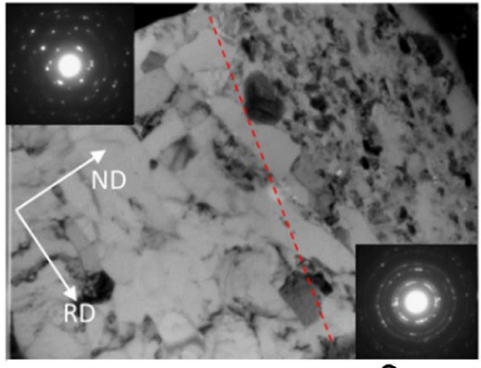

(c)

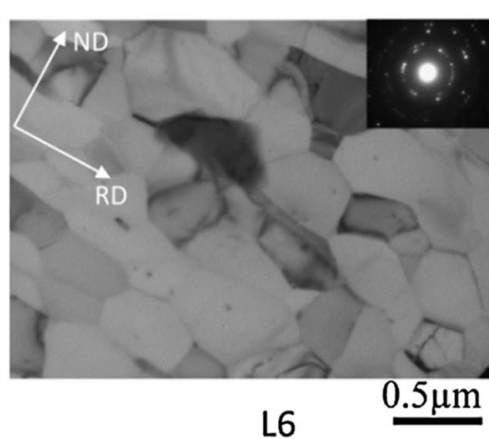

(f)

Fig. 4-Microstructure evolutions during the ARB processing without the preheat treatment. Insets are corresponding selected area diffraction patterns. 
material (Figure 3) distribute relatively dispersedly, whereas after one cycle of ARB processing, the distribution of the $\{111\}$ diffraction spots shows obvious concentration (Figure a and $d$ ). In the presence of a uniaxial applied load, in this situation, it is easy to activate the slip systems simultaneously in these grains, which results in deformation concentration, thereby leading to necking and displaying low plasticity. The $\{111\}$ diffraction spots for the samples after three cycles of ARB processing show dispersed distribution again (Figure 4(b)) and almost form a ring in the edge position of the sample (Figure 4(e)). In this situation, the uniaxial applied load may activate relatively more slip systems in the misoriented grains and the necking can be postponed by the harmonized deformation of the adjacent grains. The smooth flow stress platform shown in Figure 1 also indicates the delay of necking in the sample after three cycles of ARB processing. Therefore, the elongation is relatively increased compared to that of the sample after one cycle of ARB processing. Moreover, since the dislocations and grain boundaries have been significantly increased in this stage, the strength was also increased due to the interaction of dislocations and grain boundaries. ${ }^{[6-8]}$

After six cycles of ARB processing, the work hardening became obvious and played the dominant role. Therefore, the sample shows the highest strength and lowest plasticity (Figure 1). Besides, it is difficult for recrystallization to take place in the early stages of ARB processing, because there was no preheat treatment and the deformation energy has not been accumulated yet. With more cycles of ARB processing, the work hardening and deformation resistance increased and then resulted in temperature increase. Consequently, the stored deformation energy may release and induce dynamic recrystallization in the local area (Figure 4(c)). In the edge position of the sample, since the material is close to the rolls, the temperature was relatively low and the recrystallization did not take place. Moreover, due to the large shear deformation here, it shows a fine equiaxed grain microstructure.

Kim et al. ${ }^{[21]}$ have also shown in their results that the region of the steady state for the AA8011 Al alloy increased with increasing ARB cycles and the total elongation of the AA8011 sheets significantly increased with an increasing number of ARB cycles (strain) and reached 18 pct after 12 cycles. They suggested that this increase in total elongation corresponds well with the fact that recovery was enhanced in the UFG AA8011 alloy due to a larger fraction of high angle boundaries and purer Al matrix. So far, this unexpected phenomenon has been reported in a series of Al or Al alloys and IF steels. ${ }^{[19-21]}$ Therefore, this phenomenon might be a particular feature of the UFG materials and should be further investigated.

\section{CONCLUSIONS}

In this paper, sheets of commercial purity Al were fabricated by the accumulative roll-bonding (ARB) method up to six cycles without preheat treatment and lubricant. The strength has been significantly increased by the ARB processing. Interesting, the elongation was also relatively increased during the first several cycles of ARB processing. The SAD patterns demonstrate that the ARB processing is able to change the material texture. Microstructure investigation shows that an ultrafine microstructure was obtained after six cycles of ARB processing. In the center of the sample, the grains were elongated first and then formed ultrafine grains after six cycles of ARB processing. Besides, recrystallization took place in some area due to the deformation energy release. In the edge position of the sample, the microstructure tended to transfer from initial micrograins to fine equiaxed grains due to the large shear deformation.

\section{REFERENCES}

1. Y. Saito, N. Tsuji, H. Utsunomiya, T. Sakai, and R.G. Hong: Scripta Mater., 1998, vol. 39, p. 1221.

2. Y. Saito, H. Utsunomiya, N. Tsuji, and T. Sakai: Acta Mater., 1999, vol. 47, p. 579.

3. N. Tsuji, K. Shiotsuki, and Y. Saito: Mater. Trans., JIM, 1999, vol. 40 , p. 765 .

4. L.L. Shaw: $J$ Metals (JOM), 2000, vol. 52, p. 41

5. B.S. Altan, I. Miskioglu, G. Purcek, R.R. Mulyukov, and R. Artan: Severe Plastic Deformation: Towards Bulk Production of Nanostructured Materials, NOVA Science Publishers, New York, 2006.

6. M.A. Meyers, A. Mishra, and D.J. Benson: Prog. Mater Sci., 2006, vol. 51, p. 427.

7. R.Z. Valiev, R.K. Islamgaliev, and I.V. Alexandrov: Prog. Mater Sci., 2000, vol. 45, p. 103.

8. R.Z. Valiev and T.G. Langdon: Prog. Mater Sci., 2006, vol. 51, p. 881 .

9. N.A. Smirnova, V.I. Levit, V.I. Pilyugin, R.I. Kuznetsov, L.S. Davydova, and V.A. Sazonova: Fiz. Met. Metalloved., 1986, vol. 61 , p. 1170 .

10. G. Rogl, D. Setman, E. Schafler, J. Horky, and M. Kerber: Acta Mater., 2012, vol. 60, p. 2146.

11. R.Z. Valiev, O.A. Kaibyshev, R.I. Kuznetsov, R.Sh. Musalimov, and N.K. Tsenev: Proc. USSR Acad. Sci., 1988, vol. 301, p. 864.

12. A.P. Zhilyaev, G.V. Nurislamova, B.K. Kim, M.D. Baro, J.A. Szpunar, and T.G. Langdon: Acta Mater., 2003, vol. 51, p. 753.

13. R.Z. Valiev, N.A. Krasilnikov, and N.K. Tsenev: Mater. Sci. Eng., 1991, vol. A137, p. 35.

14. V.M. Segal, V.I. Reznikov, A.E. Drobyshevskiy, and V.I. Kopylov: Russ. Metall., 1981, vol. 1, p. 99.

15. V.M. Segal: Mater. Sci. Eng. A, 1995, vol. 197, p. 157.

16. V.M. Segal, S.V. Dobatkin, R.Z. Valiev, eds.: Russian Metall. vol. 2004, no. 1, p. 1-102.

17. W.J. Kim, M.J. Kim, and J.Y. Wang: Mater. Sci. Eng. A, 2009, vol. 516, p. 17.

18. X. Huang, N. Hansen, and N. Tsuji: Science, 2006, vol. 312, p. 249.

19. X. Huang, N. Kamikawa, and N. Hansen: Mater. Sci. Eng. A, 2008, vol. 493, p. 184.

20. N. Kamikawa, X. Huang, N. Tsuji, and N. Hansen: Acta Mater., 2009, vol. 57, p. 4198.

21. H.W. Kim, S.B. Kang, N. Tsuji, and Y. Minamino: Acta Mater., 2005, vol. 53, p. 1737. 